\title{
Determinants of vitamin D status in young children: results from the Belgian arm of the IDEFICS /Identification and Prevention of Dietary- and Lifestyle-Induced Health Effects in Children and Infants) Study
}

\author{
Isabelle Sioen 1,2,*, Theodora Mouratidou ${ }^{3}$, Jean-Marc Kaufman ${ }^{4,5}$, Karin Bammann ${ }^{6}$, \\ Nathalie Michels ${ }^{1}$, Iris Pigeot ${ }^{6}$, Barbara Vanaelst ${ }^{1,2}$, Krishna Vyncke ${ }^{1,2}$ and \\ Stefaan De Henauw ${ }^{1,7}$ on behalf of the IDEFICS consortium \\ 'Department of Public Health, Ghent University, UZ 2 Blok A, De Pintelaan 185, B-9000 Ghent, Belgium: \\ ${ }^{2}$ FWO, Research Foundation Flanders, Belgium: ${ }^{3}$ GENUD (Growth, Exercise, Nutrition and Development) \\ Research Group, University of Zaragoza, Zaragoza, Spain: ${ }^{4}$ Department of Endocrinology, Ghent University, \\ Ghent, Belgium: ${ }^{5}$ Unit for Osteoporosis and Metabolic Bone Diseases, Ghent University Hospital, Ghent, \\ Belgium: ${ }^{6}$ Bremen Institute for Prevention Research and Social Medicine, University of Bremen, Bremen, \\ Germany: ${ }^{7}$ Department of Health Sciences, Vesalius Hogeschool Gent, Ghent, Belgium
}

Submitted 7 June 2011: Accepted 11 October 2011: First published online 8 December 2011

\begin{abstract}
Objective: To describe the vitamin D status of Belgian children and examine the influence of non-nutritional determinants, in particular of anthropometric variables. Design: Cross-sectional data of Belgian participants of the EU 6th Framework Programme IDEFICS (Identification and Prevention of Dietary- and LifestyleInduced Health Effects in Children and Infants) Study.

Setting: 25-Hydroxyvitamin D (25(OH)D) was measured using RIA. Vitamin D status was categorized as deficient $(<25 \mathrm{nmol} / \mathrm{l})$, insufficient $(25-50 \mathrm{nmol} / \mathrm{l})$, sufficient $(50-75 \mathrm{nmol} / \mathrm{l})$ and optimal $(\geq 75 \mathrm{nmol} / \mathrm{l})$. Anthropometric measurements included height, weight, waist and hip circumferences and triceps and subscapular skinfold thicknesses.

Subjects: Children ( $n$ 357) aged 4-11 years.

Results: Serum 25(OH)D ranged from 13.6 to $123.5 \mathrm{nmol} / 1$ (mean $47 \cdot 2$ (SD 14.6 ) nmol/1); with 5\% deficient, 53\% insufficient, $40 \%$ sufficient and $2 \%$ optimal. No significant differences were found by age and gender. Significant differences in $25(\mathrm{OH}) \mathrm{D}$ were observed for month of sampling $(P<0 \cdot 001)$, number of hours playing outside per week $(r=0 \cdot 140)$, weight $(r=-0 \cdot 121)$, triceps $(r=-0 \cdot 112)$ and subscapular $(r=-0 \cdot 119)$ skinfold thickness, sum of two skinfold thicknesses $(r=-0 \cdot 125)$ and waist circumference $(r=-0 \cdot 108)$. Linear regression analysis of $25(\mathrm{OH}) \mathrm{D}$ adjusted for age, month of sampling and hours playing outside per week suggested that (i) weight, (ii) BMI Z-score, (iii) waist circumference and (iv) triceps and subscapular skinfold thickness (as well as the sum of both) independently influenced 25(OH)D.

Conclusions: The majority of Belgian children had a suboptimal vitamin D status, with more than half having an insufficient status in winter and spring. Month of the year, weekly number of hours playing outside and body composition - both central and abdominal obesity - were identified as important determinants of vitamin D status in Belgian children.
\end{abstract}

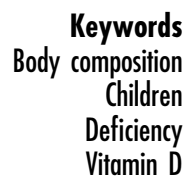

Vitamin D is an important determinant of bone health at all ages ${ }^{(1)}$. Vitamin D increases the absorption of Ca and phosphate from the gastrointestinal tract for mineralization of the skeleton. In utero and during childhood, vitamin D deficiency can cause growth retardation and skeletal deformities and is associated with an increased risk of hip fracture later in life $\mathrm{e}^{(1-3)}$. In addition to its role in bone health, vitamin $\mathrm{D}$ has also been reported as a relevant factor in decreasing the risk of many chronic illnesses including common cancers and autoimmune, infectious and cardiovascular diseases ${ }^{(3)}$. Recently, Gilbert-Diamond et $a{ }^{(4)}$ demonstrated an inverse association between vitamin D serostatus and the development of adiposity in Colombian school-aged children. 
Vitamin D deficiency and insufficiency are still very common, especially in high-risk groups such as young children $^{(3,5)}$. Humans get vitamin D from exposure to sunlight, from their diet and from dietary supplements. Previous studies showed that the dietary vitamin D intake of Belgian children and adolescents is very low compared with the Belgian recommendations ${ }^{(6,7)}$. However, no recent data on vitamin D status in young children living in Belgium are available. Moreover, most studies describing the vitamin D status of European children start at the age of 8 years and older ${ }^{(8-13)}$. Additionally, different anthropometric variables have been shown to significantly influence vitamin D status. Recently, Rodríguez-Rodríguez et al. ${ }^{(11)}$ suggested that the amount of visceral and not subcutaneous fat determines the serum level of vitamin D in children (9-13 years old), but concluded that more studies are needed to test this hypothesis and to confirm their findings.

The study presented here describes cross-sectional data on the vitamin D status of Belgian children aged between 4 and 11 years, based on the serum concentration of 25-hydroxyvitamin D (25(OH)D) in blood samples taken in winter and spring, and aims to assess the influence of non-nutritional determinants on vitamin D status.

\section{Experimental methods}

\section{Participants}

Participating children were drawn from the Belgian control region cohort of the EU 6th Framework Programme IDEFICS Study, residents from the city of Aalter $\left(51^{\circ} 05^{\prime} \mathrm{N}\right)$ in the northern Dutch-speaking part of Belgium. The IDEFICS (Identification and prevention of Dietary- and lifestyle-induced health EFfects In Children and infantS; http://www.idefics.eu) multicentre study is a European project in eight European countries. IDEFICS is a longitudinal study; however, in the present paper only the cross-sectional data collected in 2010 are used. The children were contacted by random cluster sampling (all children from a selection of classes from all schools in the control city) ${ }^{(14-16)}$. During the fieldwork period, which ran from February 2010 to June 2010, a venous blood collection was received from 509 children in the Belgian IDEFICS control region. Vitamin D analysis was performed on the samples of 358 children. Blood drawn from the rest of the children was not sufficient to allow analysis, since the first six aliquots were analysed for other purposes of the IDEFICS Study. For one child, information on sex was missing. Therefore, the data of 357 children were used for the purposes of the present analysis. Concerning the ethnicity of the children, of the 357, only seven were not born in Belgium (four of the seven were born within the EU). For the children who were born in Belgium, only two had one parent born outside Belgium (one from Cuba and one from the Philippines). The study was conducted according to the guidelines laid down in the Helsinki Declaration of the World Medical Association and the project protocol was approved by the Ethical Committee of Ghent University Hospital. All parents of the participating children gave written informed consent.

\section{Questionnaire}

A self-administered parental questionnaire was used to obtain information on the following variables: number of hours playing outside during weekdays and weekend days, use of vitamin supplements, birth weight and fractures. Questions assessing the number of hours playing outside were based on those used in Burdette et al. ${ }^{(17)}$.

\section{Antbropometric measurements and body composition}

All anthropometric measurements were done by two trained researchers. Height and weight were measured respectively with a standard clinical Seca 225 stadiometer (Seca GmbH \& Co. KG, Hamburg, Germany) to the nearest $0 \cdot 1 \mathrm{~cm}$ and a balance (Tanita BC 420 SMA; Tanita, Amsterdam, The Netherlands) to the nearest $0.1 \mathrm{~kg}$, without shoes and in light clothing. The Tanita balance was calibrated and did not need further calibration; also the Seca stadiometer needed neither maintenance nor further calibration. BMI was calculated according to the formula: $\mathrm{BMI}=$ weight $(\mathrm{kg}) /[\text { height }(\mathrm{m})]^{2}$. For each child, weight, height and BMI $Z$-score and the International Obesity Taskforce grade was determined using the LMS method (with British reference population) which summarizes the distribution of weight, height and BMI at each age by its median and $\mathrm{CV}$, plus a measure of skewness based on the Box-Cox power required to transform the data to normality ${ }^{(18)}$. Waist and hip circumferences were measured using a Seca 200 inelastic tape (Seca $\mathrm{GmbH} \&$ Co. KG; precision $0 \cdot 1 \mathrm{~cm}$, range $0-150 \mathrm{~cm}$ ). This tape did not need any calibration. Skinfold thickness was measured at the previously marked points using Holtain Tanner/Whitehouse skinfold callipers (Holtain Ltd, Crosswell, UK; range $0-40 \mathrm{~mm}$ ). The callipers were calibrated every morning and additionally when dropped by means of a calibration block of $20 \mathrm{~mm}$. Skinfold thickness was measured at two sites (triceps and subscapular) according to the international standards for anthropometric assessment (International Society for the Advancement of Kinanthropometry ${ }^{(19)}$. Skinfold thickness was measured twice at each site and the mean of both measurements was calculated. For the different body composition parameters, mean $Z$-scores were calculated using the formula: $Z=(X-\mu) / \mathrm{sD}$, with $X$ the measured value, $\mu$ the mean and SD the standard deviation of the parameter.

\section{Biochemical analysis}

Fasting blood samples $(10 \mathrm{ml})$ were drawn by venepuncture by a medical doctor. The serum was separated, aliquoted and stored at $-80^{\circ} \mathrm{C}$ until analysis. $25(\mathrm{OH}) \mathrm{D}$ concentrations were measured by RIA (DiaSorin 25(OH)D - ${ }^{125}$ I RIA kit, 
Stillwater, MN, USA). The inter-assay CV for low and higher $25(\mathrm{OH}) \mathrm{D}$ controls was $6 \cdot 2 \%$ and $6.5 \%$, respectively, whereas the intra-assay $\mathrm{CV}$ was $8 \cdot 4 \%$ and $7 \cdot 3 \%$ for low and higher $25(\mathrm{OH})$ controls, respectively. For validation of the vitamin D assay, the laboratory participates in the External Quality Assessment Scheme of SKML (Stichting Kwaliteitsbewaking Medische Laboratoriumdiagnostiek) from The Netherlands, which six times a year gives two samples of vitamin D controls.

\section{Statistical analysis}

Pearson correlation coefficients were calculated to investigate correlations between vitamin D status and other continuous variables. Differences in vitamin D status between two groups (sex, (non-)use of vitamin D supplements and (not) having had fractures in the past) were examined by the independent-samples $t$ test. When more than two groups were considered, ANOVA was used. In addition, as exploratory analysis, the post boc Tukey Honestly Significant Difference (HSD) test was performed to make pairwise comparisons.

The independent contribution of non-nutritional determinants (age, gender, month of sampling, number of hours playing outside per week) to the variance in vitamin D status was examined by analysis of covariance (ANCOVA). Two ANCOVA models were constructed using two different indicators of body composition: (i) the sum of two skinfold thicknesses, reflecting the amount of subcutaneous fat; and (ii) waist circumference, reflecting the amount of abdominal fat. Both body composition parameters were log-transformed to obtain normality in these variables. Only significant variables associated with vitamin D status were included in the final model. The effect of clustering was investigated using mixed model analyses, with 'school' being the nested variable and taking on board the same covariates and interaction factors as was done in the ANCOVA model.

Relationships between vitamin D status and related anthropometric variables (weight, height, BMI Z-score, waist circumference, waist:hip ratio, waist:height ratio, triceps skinfold thickness, subscapular skinfold thickness, sum of two skinfold thicknesses) were quantified using linear regression, controlling for age, month of sampling and number of hours playing outside per week. For these analyses, the month of sampling was dummy coded (March and April =0; May and June $=1$; the cases of February ( $n$ 29) were excluded).

All analyses were performed using the SPSS for Windows statistical software package version $15 \cdot 0$ (SPSS Inc., Chicago, IL, USA), and values of $P<0.05$ were considered statistically significant.

\section{Results}

Characteristics and anthropometric variables of the population sample are summarized in Table 1. Serum 25(OH)D ranged from $13.6 \mathrm{nmol} / 1$ to $123.5 \mathrm{nmol} / 1$, with a mean concentration of $47 \cdot 2(\mathrm{SD} 14 \cdot 6) \mathrm{nmol} / \mathrm{l}$.

No significant difference in vitamin $D$ status was found between boys and girls $(P=0 \cdot 263)$. Children using

Table 1 Characteristics, serum 25(OH)D concentrations and anthropometric data of the study population: Belgian children aged 4-11 years participating in the IDEFICS Study, 2010

\begin{tabular}{|c|c|c|c|}
\hline \multirow[b]{2}{*}{ Variable } & \multicolumn{3}{|c|}{ Study sample ( $n$ 357) } \\
\hline & Mean or \% & SD & $Z$-score \\
\hline Age (years) & $8 \cdot 1$ & $1 \cdot 5$ & \\
\hline Gender: male (\%) & $51 \cdot 5$ & & \\
\hline Born in Belgium (\%) & $98 \cdot 0$ & & \\
\hline Serum $25(O H) D$ concentration (nmol/l) & $47 \cdot 2$ & $14 \cdot 6$ & \\
\hline Serum $25(\mathrm{OH}) \mathrm{D}$ concentration $<25 \mathrm{nmol} / \mathrm{l}(\%)$ & 5 & & \\
\hline Serum $25(\mathrm{OH}) \mathrm{D}$ concentration between 25 and $50 \mathrm{nmol} / \mathrm{l}(\%)$ & 53 & & \\
\hline Serum 25(OH)D concentration between 50 and $75 \mathrm{nmol} / \mathrm{l}(\%)$ & 40 & & \\
\hline Serum $25(\mathrm{OH}) \mathrm{D}$ concentration $>75 \mathrm{nmol} / \mathrm{l}(\%)$ & 2 & & \\
\hline Number of hours playing outside (h/week) & $14 \cdot 0$ & $8 \cdot 5$ & \\
\hline Vitamin D supplement: yes (\%) & $5 \cdot 9$ & & \\
\hline Fracture: yes (\%) & $12 \cdot 6$ & & \\
\hline Weight $(\mathrm{kg})$ & $27 \cdot 0$ & $5 \cdot 7$ & 0.078 \\
\hline Height $(\mathrm{cm})$ & $130 \cdot 0$ & $10 \cdot 1$ & 0.456 \\
\hline BMI $\left(\mathrm{kg} / \mathrm{m}^{2}\right)$ & $15 \cdot 8$ & $0 \cdot 1$ & -0.267 \\
\hline \multicolumn{4}{|l|}{ BMI (\%) } \\
\hline Underweight & $13 \cdot 4$ & & \\
\hline Normal weight & $81 \cdot 5$ & & \\
\hline Overweight & $5 \cdot 0$ & & \\
\hline Triceps skinfold thickness (mm) & $10 \cdot 2$ & $3 \cdot 5$ & 0.018 \\
\hline Subscapular skinfold thickness (mm) & $6 \cdot 4$ & $2 \cdot 8$ & 0.007 \\
\hline Waist circumference $(\mathrm{cm})$ & $56 \cdot 3$ & $5 \cdot 4$ & 0.032 \\
\hline Waist:hip ratio & $0 \cdot 85$ & $0 \cdot 12$ & -0.002 \\
\hline Waist:height ratio & 0.43 & $0 \cdot 04$ & $0 \cdot 117$ \\
\hline
\end{tabular}


vitamin D-containing supplements (5.9\%) had a mean $25(\mathrm{OH}) \mathrm{D}$ concentration of $49 \cdot 5(\mathrm{sD} 11 \cdot 2) \mathrm{nmol} / \mathrm{l}$ compared with $47 \cdot 0(\mathrm{SD} 15 \cdot 2) \mathrm{nmol} / 1$ for those not using vitamin Dcontaining supplements; however, the difference was not significant $(P=0 \cdot 464)$. On the same line, no significant difference $(P=0 \cdot 302)$ was found between those children who reported having had a fracture (12.6\%) so far $(25(\mathrm{OH}) \mathrm{D}=44.9(\mathrm{sD} 13.7) \mathrm{nmol} / \mathrm{l})$ and those without any reported fractures $(25(\mathrm{OH}) \mathrm{D}=47 \cdot 3(\mathrm{sD} 13 \cdot 7) \mathrm{nmol} / \mathrm{l})$.

ANOVA did not show any significant difference in 25(OH)D concentration for different birth months $(P=0 \cdot 160)$. However, a significant difference in $25(\mathrm{OH}) \mathrm{D}$ concentration between the months of sampling (February to June) was found $(P<0 \cdot 001)$. The post hoc Tukey HSD test indicated a difference between March and May $(P<0 \cdot 001)$,

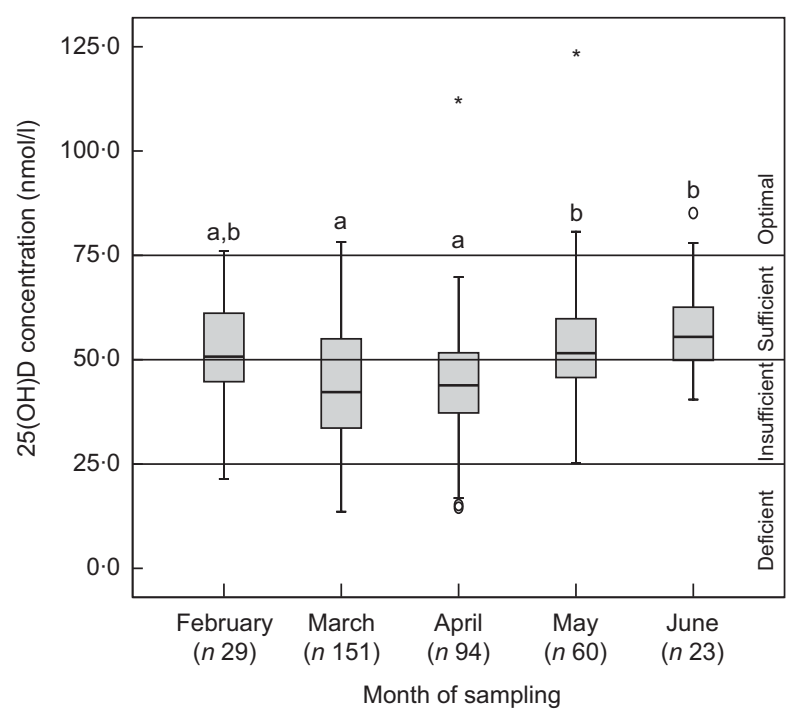

Fig. 1 Box plot of serum 25-hydroxyvitamin D (25(OH)D) concentrations in Belgian children aged 4-11 years participating in the IDEFICS (Identification and Prevention of Dietary- and Lifestyle-Induced Health Effects in Children and Infants) Study, 2010 , according to month of sampling. ${ }^{\mathrm{a}, \mathrm{b}}$ Mean values with unlike superscript letters were significantly different $(P<0.05)$; $\bigcirc$, outlier; *, extreme value
March and June $(P<0 \cdot 001)$, April and May $(P=0 \cdot 007)$ and April and June $(P=0 \cdot 002)$, as illustrated in Fig. 1.

Table 2 shows the correlation coefficients between $25(\mathrm{OH}) \mathrm{D}$ concentration and several covariates of interest. A positive significant correlation $(r=0 \cdot 140)$ was found between $25(\mathrm{OH}) \mathrm{D}$ concentration and the number of hours playing outside per week. Moreover, negative correlations were found between $25(\mathrm{OH}) \mathrm{D}$ concentration and weight $(r=-0 \cdot 121)$, triceps $(r=-0 \cdot 112)$ and subscapular $(r=-0 \cdot 119)$ skinfold thickness, the sum of two skinfold thicknesses $(r=-0 \cdot 125)$ and waist circumference $(r=-0 \cdot 108)$.

The results of the ANCOVA models are shown in Table 3. The adjusted $R^{2}$ (coefficient of determination) of the first (with skinfold thickness) and second (with waist circumference) model was $0 \cdot 126$ and $0 \cdot 118$, respectively. Both models indicated a significant contribution of the month of sampling, the number of hours playing outside per week and the included body composition parameter (reflecting respectively subcutaneous and abdominal fat) to the variance in $25(\mathrm{OH}) \mathrm{D}$ concentration.

The mixed model analyses indicated that the cluster random sampling design of the study (via schools) did not have an influence on the study results $(P=0 \cdot 198)$.

Using linear regression analyses with serum $25(\mathrm{OH}) \mathrm{D}$ concentration as the dependent variable and controlling for age, month of sampling and number of hours playing outside per week, it was found that weight, BMI $Z$-score, waist circumference and triceps and subscapular skinfold thickness (as well as the sum of both) independently influenced these concentrations (Table 4).

\section{Discussion}

The present paper describes the vitamin D status of Belgian children aged 4-11 years. The optimal vitamin D levels for health remain a subject of debate ${ }^{(3)}$. In the present paper four categories were considered: category 1 , $<25 \mathrm{nmol} / \mathrm{l}$, deficient; category 2, 25-50 nmol/1, insufficient;

Table 2 Pearson correlation coefficients between 25(OH)D concentration and several covariates: Belgian children aged $4-11$ years participating in the IDEFICS Study, 2010

\begin{tabular}{lcc}
\hline & Pearson correlation coefficient & $P$ value \\
\hline Age (years) & -0.030 & 0.578 \\
Number of hours playing outside per week & 0.140 & $0.011^{*}$ \\
Weight (kg) & -0.121 & $0.022^{\star}$ \\
Height (cm) & -0.070 & 0.188 \\
BMl Z-score & -0.080 & 0.131 \\
Triceps skinfold thickness (mm) & -0.112 & $0.034^{\star}$ \\
Subscapular skinfold thickness (mm) & -0.119 & $0.025^{*}$ \\
Sum of triceps and subscapular skinfold thickness (cm) & -0.125 & $0.018^{*}$ \\
Waist (cm) & -0.108 & $0.042^{\star}$ \\
Waist:hip ratio & -0.097 & 0.068 \\
Waist:height ratio & -0.038 & 0.472
\end{tabular}

25(OH)D, 25-hydroxyvitamin D; IDEFICS, Identification and Prevention of Dietary- and Lifestyle-Induced Health Effects in Children and Infants. *Significant at level $P=0.05$. 
Table 3 Results of the two ANCOVA models assessing the independent contributions of determinants to the variance in 25(OH)D concentration: Belgian children aged 4-11 years participating in the IDEFICS Study, 2010

\begin{tabular}{|c|c|c|}
\hline & $F$ factor & $P$ value \\
\hline \multicolumn{3}{|l|}{ First model (adjusted $R^{2}=0.126$ ) } \\
\hline Month of sampling & $3 \cdot 4$ & $0.009^{*}$ \\
\hline Interaction between month of sampling and hours playing outside per week & $3 \cdot 2$ & $0.007^{*}$ \\
\hline Sum of triceps and subscapular skinfold thickness & $8 \cdot 2$ & $0.004^{*}$ \\
\hline \multicolumn{3}{|l|}{ Second model (adjusted $R^{2}=0 \cdot 118$ ) } \\
\hline Month of sampling & $3 \cdot 2$ & $0 \cdot 014^{*}$ \\
\hline Interaction between month of sampling and hours playing outside per week & $2 \cdot 9$ & $0.013^{*}$ \\
\hline Waist circumference & $6 \cdot 7$ & $0 \cdot 010^{*}$ \\
\hline
\end{tabular}

ANCOVA, analysis of covariance; 25(OH)D, 25-hydroxyvitamin D; IDEFICS, Identification and Prevention of Dietary- and LifestyleInduced Health Effects in Children and Infants.

*Significant at level $P=0.05$.

Table 4 Regression results using 25(OH)D concentration as the dependent variablet: Belgian children aged 4-11 years participating in the IDEFICS Study, 2010

\begin{tabular}{lcl}
\hline & Standardized coefficient $\beta$ value & $P$ value \\
\hline Weight $(\mathrm{kg})$ & -0.234 & $0 \cdot 001^{*}$ \\
Height $(\mathrm{cm})$ & -0.188 & 0.053 \\
BMl Z-score $\left(\mathrm{kg} / \mathrm{m}^{2}\right)$ & -0.119 & $0.029^{*}$ \\
Waist circumference $(\mathrm{cm})$ & -0.153 & $0.010^{*}$ \\
Waist:hip ratio & -0.090 & $0 \cdot 121$ \\
Waist:height ratio & -0.094 & $0 \cdot 107$ \\
Triceps skinfold thickness $(\mathrm{mm})$ & -0.163 & $0.012^{*}$ \\
Subscapular skinfold thickness $(\mathrm{mm})$ & -0.140 & $0.010^{*}$ \\
Sum of two skinfold thicknesses $(\mathrm{mm})$ & -0.153 & $0.005^{*}$
\end{tabular}

25(OH)D, 25-hydroxyvitamin D; IDEFICS, Identification and Prevention of Dietary- and Lifestyle-Induced Health Effects in Children and Infants.

${ }^{*}$ Significant at level $P=0.05$.

tConfounding variables (age, month of sampling and number of hours playing outside per week) have been taken into account in the statistical analysis.

category 3, 50-75 nmol/1, sufficient; and category 4, $\geq 75 \mathrm{nmol} / 1$, optimal. These categories are based on recent publications taking into account the full advantage of all the health benefits that vitamin D provides ${ }^{(3,5,20)}$. More specifically for children, the Pediatric Endocrine Society stated that $50 \mathrm{nmol} / \mathrm{l}$ is the lower end of the optimal $25(\mathrm{OH}) \mathrm{D}$ concentration in children ${ }^{(21)}$. Within our study sample of Belgian children, $58 \%$ had an insufficient vitamin D status and only a small proportion $(2 \cdot 2 \%)$ reached the optimal level, based on blood sampled in winter and spring. Until now, recent data on the vitamin D status of Belgian young children had not been available. Evidence on the vitamin D status of other European children up to 10 years is limited as well, most including an older age group.

\section{Comparison with otber European data}

The data of the present study were compared with other available European data; however, this comparison must be interpreted with caution, as not all the studies used the same method of determining $25(\mathrm{OH}) \mathrm{D}$ which can influence the results. At the end of the last millennium, data were published on the vitamin D status of French, Spanish and Finnish children aged 13-17 years, 8-12 years and 9-15 years, respectively ${ }^{(8-10)}$. In the French children (only males), a mean $25(\mathrm{OH}) \mathrm{D}$ concentration of $58.5 \mathrm{nmol} / 1$ was found after summer and $20.6 \mathrm{nmol} / 1$ was found after winter ${ }^{(10)}$.
Similarly, in the Spanish children, a mean of 74.8 and $31.5 \mathrm{nmol} / 1$ was determined in October and March, respectively ${ }^{(9)}$. This illustrates a strong effect of the season of sampling, similarly to that observed in our study (e.g. March $v$. June; Fig. 1). The Finnish study, which included only girls, indicated a mean $25(\mathrm{OH}) \mathrm{D}$ concentration of $33.9 \mathrm{nmol} / \mathrm{l}^{(8)}$, lower than the mean found in the present study. More recent publications describing the vitamin D status in European children, in Spain (9-13 years) ${ }^{(11)}$, in Northern Ireland (12-15 years) ${ }^{(12)}$ and in a combined cohort of Finnish and Danish girls (11 years old $)^{(13)}$, indicated higher concentrations compared with our Belgian sample. For instance, mean $25(\mathrm{OH}) \mathrm{D}$ concentrations in Spain were $49 \cdot 6 \mathrm{nmol} / \mathrm{l}^{(11)}$, in Northern Ireland were $56 \cdot 7 \mathrm{nmol} / 1$ (winter) and $78.1 \mathrm{nmol} / 1$ (summer), in the Danish and Finnish girls were $57 \cdot 2$ and $56 \cdot 2 \mathrm{nmol} / 1$, respectively ${ }^{(13)}$, as opposed to $47 \cdot 2 \mathrm{nmol} / 1$ in our sample. We found no significant differences by gender, unlike the Spanish and Northern Irish populations where significant differences by gender were observed. However our study population was younger and this age difference could have an influence on gender differences.

\section{Determinants of vitamin $D$ status}

The ANCOVA yielded three important non-nutritional determinants of the vitamin D status in Belgian young 
children: month of sampling, number of hours playing outside per week and body composition. The first two parameters are related to the fact that solar UV-B radiation converts and modifies 7-dehydrocholesterol into vitamin D at skin temperature ${ }^{(2)}$. In northern countries, such as Belgium, there is no UV radiation of the appropriate wavelength from the end of October to the end of March ${ }^{(22)}$. This is clearly illustrated in Fig. 1, showing a minimum in 25(OH)D in March and an increase from April on. Moreover, the study results showed an interaction effect of season and the weekly number of hours playing outside, since the highest levels of outdoor playtime occur in summer and the lowest in winter ${ }^{(17)}$.

Body composition is another important determinant of vitamin D status. Previous studies have suggested that vitamin D deficiency is associated with excess body weight mainly due to the fact that body fat could function as a sink for vitamin $\mathrm{D}$, which is fat soluble ${ }^{(23-25)}$. Moreover, inadequate vitamin D status could also be a risk factor for childhood obesity, since it affects lipolysis and adipogenesis in human adipocytes ${ }^{(26-29)}$. In the present study, it was found that parameters of whole-body obesity (defined by the BMI), parameters of subcutaneous fat (skinfold thickness) as well as parameters of abdominal fat (waist circumference) independently influenced vitamin D status in young Belgian children (4-11 years old). The study of Spanish children (9-13 years) ${ }^{(11)}$ also concluded that BMI and abdominal obesity influenced the appearance of vitamin D insufficiency in children. However, the Spanish study did not find a difference in terms of the amount of subcutaneous fat between the children with insufficient vitamin D levels and the children with adequate levels. The difference concerning this finding between both studies can possibly be influenced by the difference in age (on average $8 \cdot 1$ years in Belgium v. 10.9 years in Spain), resulting in lower weight, height, BMI, triceps skinfold thickness and waist circumference in Belgium compared with Spain.

\section{Strengths and limitations}

The availability of various anthropometric parameters measured in a standardized way in a relatively large sample is one of the strengths of the present study. In this way the authors had the opportunity to address the influence of various anthropometric indicators on vitamin D status and explore possible relationships and interactions. The present study is one of the first addressing this issue in young children, based on the hypothesis suggested by Rodriguez-Rodriguez et $a l^{(11)}$. To assess vitamin D status, the serum concentration of $25(\mathrm{OH}) \mathrm{D}$ was measured, currently the best parameter for vitamin D status $^{(5,20)}$. Next, the questions assessing the number of hours playing outside were based on Burdette et al. ${ }^{(17)}$, concluding that parent-reported measures of outdoor playtime were significantly correlated to a direct measure of physical activity in children of pre-school age and are worthy of future evaluation as a survey measure.
Although the analyses controlled for several potential confounders we cannot be certain that other unmeasured confounders such as genetic variation or dietary intake have not influenced our observations. Nevertheless, concerning dietary intake, the number of food items on the Belgian market that are fortified with vitamin $\mathrm{D}$ is rather limited, i.e. margarine (mandatory fortified), growth milk and some normal milks as well as breakfast cereals (depending on the brand). More detailed figures about the dietary intake of vitamin D in Belgian pre-school children have recently been published ${ }^{(30)}$.

\section{Conclusions}

The majority of Belgian children (4-11 years old) have a suboptimal vitamin D status, with more than half having an insufficient status during winter and spring months. Month of the year, number of hours playing outside per week as well as body composition were identified as important determinants of vitamin D status in this group of children. The vitamin D status of these children was independently influenced by parameters of whole-body obesity, parameters of subcutaneous fat as well as parameters of abdominal fat. The impact of recommendations to optimize the vitamin D status of young children should be investigated in order to prevent associated diseases.

\section{Acknowledgements}

This work was done as part of the IDEFICS Study (www.idefics.eu) and was supported by the European Community within the Sixth RTD Framework Programme Contract No. 016181 (FOOD). I.S., B.V. and K.V. are financially supported by the Research Foundation Flanders (grant no. 1.2.683.11.N.00, 1.1.894.11.N.00 and 1.1.905.10.N.00, respectively). The information in this document reflects the authors' views and is provided as is. None of the authors has a conflict of interest. I.S. performed the statistical analyses and wrote the manuscript. All co-authors revised the manuscript. T.M. and I.P. provided support for the statistical analyses. K.B., I.P. and S.D.H. were involved in the design of the IDEFICS Study and the development of the questionnaires. N.M., B.V. and K.V. conducted the fieldwork. J.-M.K. was responsible for the laboratory analyses. The authors gratefully acknowledge the financial support of the European Commission and thank all participants of the IDEFICS Study in Aalter, Belgium for their involvement.

\section{References}

1. Schoenmakers I, Goldberg GR \& Prentice A (2008) Abundant sunshine and vitamin D deficiency. Br J Nutr 99, 1171-1173.

2. Cashman KD (2007) Vitamin D in childhood and adolescence. Postgrad Med J 83, 230-235. 
3. Holick MF (2007) Vitamin D deficiency. N Engl J Med 357, 266-281.

4. Gilbert-Diamond D, Baylin A, Mora-Plazas M et al. (2010) Vitamin D deficiency and anthropometric indicators of adiposity in school-age children: a prospective study. $A m J$ Clin Nutr 92, 1446-1451.

5. Lips P (2010) Worldwide status of vitamin D nutrition. J Steroid Biochem Mol Biol 121, 297-300.

6. Huybrechts I \& de Henauw S (2007) Energy and nutrient intakes by pre-school children in Flanders-Belgium. $\mathrm{Br} J$ Nutr 98, 600-610.

7. Sioen I, Matthys C, De Backer G et al. (2007) Importance of seafood as nutrient source in the diet of Belgian adolescents. J Hum Nutr Diet 20, 580-589.

8. Lehtonen-Veromaa M, Mottonen T, Irjala K et al. (1999) Vitamin D intake is low and hypovitaminosis D common in healthy 9- to 15-year-old Finnish girls. Eur J Clin Nutr $\mathbf{5 3}$, 746-751.

9. Docio S, Riancho JA, Perez A et al. (1998) Seasonal deficiency of vitamin D in children: a potential target for osteoporosis-preventing strategies? J Bone Miner Res 13, 544-548.

10. Guillemant J, Taupin P, Le HT et al. (1999) Vitamin D status during puberty in French healthy male adolescents. Osteoporos Int 10, 222-225.

11. Rodríguez-Rodríguez E, Navia-Lomban B, Lopez-Sobaler AM et al. (2010) Associations between abdominal fat and body mass index on vitamin D status in a group of Spanish schoolchildren. Eur J Clin Nutr 64, 461-467.

12. Hill TR, Cotter AA, Mitchell S et al. (2008) Vitamin D status and its determinants in adolescents from the Northern Ireland Young Hearts 2000 cohort. Br J Nutr 99, 1061-1067.

13. Cashman KD, Fitzgerald AP, Viljakainen HT et al. (2011) Estimation of the dietary requirement for vitamin $\mathrm{D}$ in healthy adolescent white girls. Am J Clin Nutr 93, 549-555.

14. Ahrens W, Bammann K, de Henauw S et al. (2006) Understanding and preventing childhood obesity and related disorders - IDEFICS: a European multilevel epidemiological approach. Nutr Metab Cardiovasc Dis 16, 302-308.

15. Bammann K, Peplies J, Sjöström M et al. (2006) Assessment of diet, physical activity and biological, social and environmental factors in a multi-centre European project on diet- and lifestyle related disorders in children (IDEFICS). J Public Health 14, 279-289.
16. Ahrens W, Bammann K, Siani A et al. (2011) The IDEFICS cohort: design, characteristics and participation in the baseline survey. Int J Obes (Lond) 35, Suppl. 1, S3-S15.

17. Burdette HL, Whitaker RC \& Daniels SR (2004) Parental report of outdoor playtime as a measure of physical activity in preschool-aged children. Arch Pediatr Adolesc Med 158, 353-357.

18. Cole TJ, Freeman JV \& Preece MA (1998) British 1990 growth reference centiles for weight, height, body mass index and head circumference fitted by maximum penalized likelihood. Stat Med 17, 407-429.

19. Marfell-Jones M, Olds T, Stewart A et al. (2006) International Standards for Anthropometric Assessment. Potchefstroom, South Africa: ISAK.

20. Holick MF (2009) Vitamin D status: measurement, interpretation, and clinical application. Ann Epidemiol 19, 73-78.

21. Wagner CL \& Greer FR (2008) Prevention of rickets and vitamin D deficiency in infants, children, and adolescents. Pediatrics 122, 1142-1152.

22. Lanham-New SA, Thompson RL, More J et al. (2007) Importance of vitamin $\mathrm{D}$, calcium and exercise to bone health with specific reference to children and adolescents. Nutr Bull 32, 364-377.

23. Bischof MG, Heinze G \& Vierhapper H (2006) Vitamin D status and its relation to age and body mass index. Horm Res 66, 211-215.

24. Wortsman J, Matsuoka LY, Chen TC et al. (2000) Decreased bioavailability of vitamin D in obesity. Am J Clin Nutr $\mathbf{7 2}$, 690-693.

25. Konradsen S, Ag H, Lindberg F et al. (2008) Serum 1,25dihydroxy vitamin $\mathrm{D}$ is inversely associated with body mass index. Eur J Nutr 47, 87-91.

26. Zemel MB, Shi H, Greer B et al. (2000) Regulation of adiposity by dietary calcium. FASEB J 14, 1132-1138.

27. Xue B, Greenberg AG, Kraemer FB et al. (2001) Mechanism of intracellular calcium $\left(\left[\mathrm{Ca}^{2+}\right]_{\mathrm{i}}\right.$ ) inhibition of lipolysis in human adipocytes. FASEB J 15, 2527-2529.

28. Wood RJ (2008) Vitamin D and adipogenesis: new molecular insights. Nutr Rev 66, 40-46.

29. Kong J \& Li YC (2006) Molecular mechanism of 1,25dihydroxyvitamin $\mathrm{D}_{3}$ inhibition of adipogenesis in 3T3-L1 cells. Am J Physiol Endocrinol Metab 290, E916-E924.

30. Huybrechts I, Lyn Y, De Keyzer W et al. (2011) Dietary sources and sociodemographic and economic factors affecting vitamin $\mathrm{D}$ and calcium intakes in Flemish preschoolers. Eur J Clin Nutr 65, 1039-1047. 